\title{
FITOCENOLOŠKA ANALIZA ŠUMA BIJELE JOHE (Alnus incana /L./ Moench subsp. incana) U HRVATSKOJ
}

\section{PHYTOCOENOLOGICAL ANALYSIS OF GREY ALDER (Alnus incana /L./ Moench supsp. incana) FORESTS IN CROATIA}

\author{
Joso VUKELIĆ ${ }^{1}$, Dario BARIČEVIĆ ${ }^{1 *}$, Igor POLJAK², Mario VRČEK, Irena ŠAPIĆ ${ }^{1}$
}

\begin{abstract}
Sažetak
U članku su prikazani rezultati fitocenoloških istraživanja i analize šumskih sastojina bijele johe (Alnus incana /L./ Moench subsp. incana) u Hrvatskoj. Na temelju 11 novih i 37 fitocenoloških snimaka iz prijašnjih istraživanja analizirane su sastojine iz Gorskoga kotara uz rijeku Kupu i njezine pritoke opisane u okviru asocijacije Lamio orvalaeAlnetum incanae Dakskobler 2010 te sastojine iz sjeverozapadne Hrvatske uz rijeku Dravu definirane kao Equiseto hyemali-Alnetum incanae Moor 1958. U radu se analizira njihov međusobni odnos, a opširnije florni sastav i dinamika promjena u sastojini bijele johe sa zimskom preslicom u sjeverozapadnoj Hrvatskoj.
\end{abstract}

KLJUČNE RIJEČI: Alnus incana, Lamio orvalae-Alnetum incanae, Equiseto hyemali-Alnetum incanae, florni sastav, Hrvatska

\section{UVOD}

\section{INTRODUCTION}

Vegetacijska istraživanja poplavnih i močvarnih šuma, a među njima i šumâ bijele johe, u posljednje su vrijeme u Europi vrlo učestala. Opisani su i analizirani različiti vegetacijski tipovi na razini pojedinih zemalja (Oberdorfer 1992; Willner i Grabherr 2007; Douda 2008; Sburlino i dr. 2012; Slezak i dr. 2013; Pielech 2015; Coldea i Ursu 2016; i dr.), zatim pojedinih regija (Dierschke 1984; Schwabe 1985; Döring-Mederake 1990; Amigo i dr. 2004; i dr.), a sintetski radovi (Douda i dr. 2016) objedinjuju ih na razini Europe. I u nas se provode opsežna vegetacijska istraživanja tih šum- skih tipova, a rezultate smo prikazali u dvama člancima (Vukelić i dr. 2012, 2017). U središtu istraživanja bila su fitocenološka obilježja sastojine bijele johe (Lamio orvalaeAlnetum incanae var. geogr. Helleborus dumetorum) u dinarskom području Hrvatske.

Bijela joha u šumskoj vegetaciji Hrvatske raste u dvama orografski i fitogeografski jasno ograničenim arealima: u sjeverozapadnom, nizinskom dijelu Hrvatske na nadmorskoj visini od 100 do $190 \mathrm{~m}$ uz tok rijeke Drave, te u gorskom, alpsko-dinarskom području uz rijeku Kupu i njezine pritoke od 220 do 550 m nadmorske visine (slika 1). Pojedinačna stabla bijele johe uz rijeku Petrinjčicu na Zrinskoj

\footnotetext{
1 Prof. dr. sc. Joso Vukelić, prof. dr. sc. Dario Baričević, dr. sc. Irena Šapić, Zavod za ekologiju i uzgajanje šuma, Šumarski fakultet Sveučilišta u Zagrebu, Svetošimunska 25, 10000 Zagreb, Hrvatska

${ }^{2}$ Dr. sc. Igor Poljak, Zavod za šumarsku genetiku, dendrologiju i botaniku, Šumarski fakultet Sveučilišta u Zagrebu, Svetošimunska 25, 10000 Zagreb, Hrvatska

${ }^{3}$ Mario Vrček, Priroda d.d., Vladimira Nazora 157, 42206 Petrijanec, Hrvatska

*dopisni autor, E-adresa: dario.baricevic@zg.htnet.hr
} 


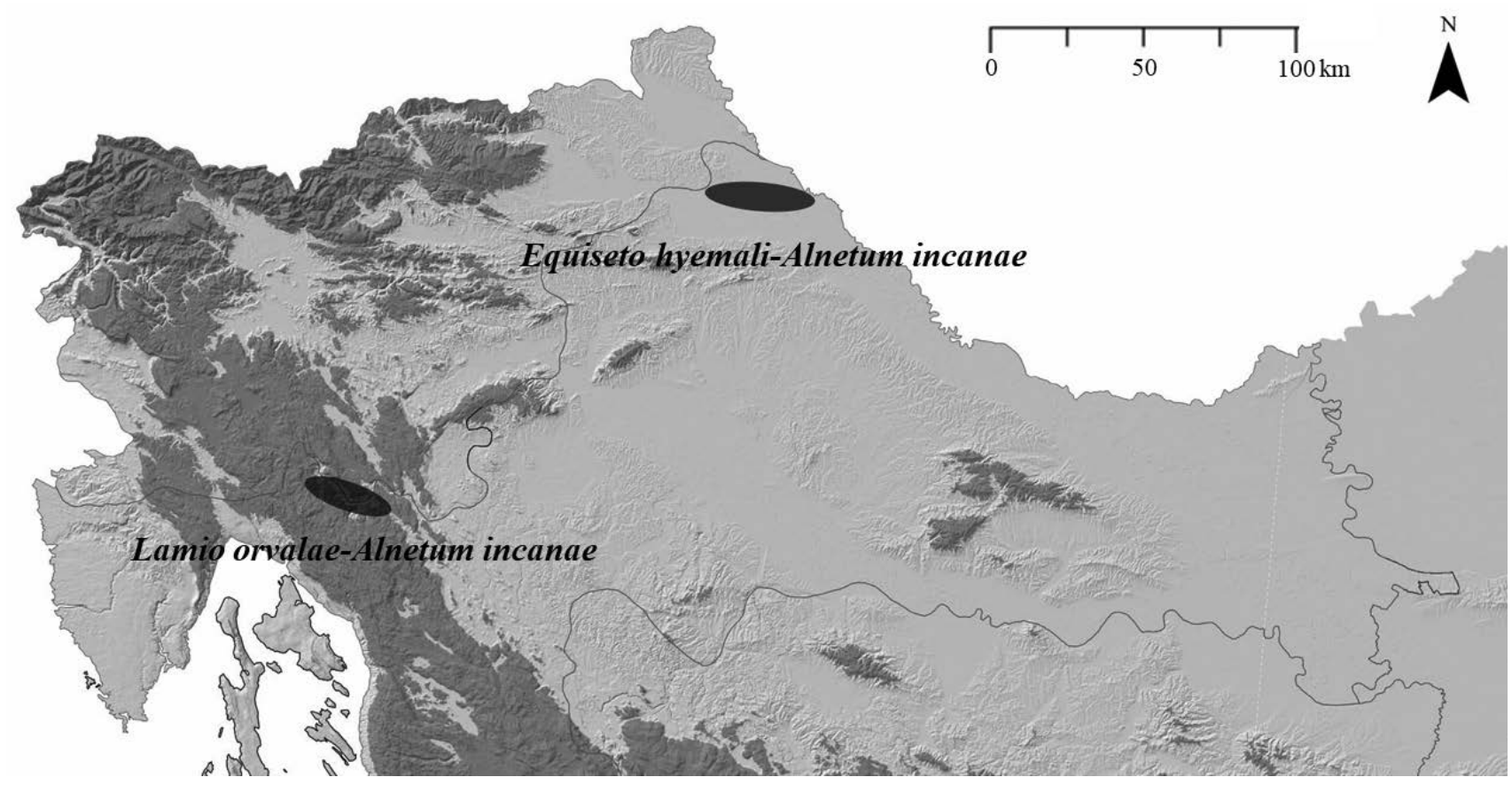

Slika 1. Istraživano područje.

Figure 1. Researched area

gori zabilježili su Šegulja i dr. (1974) i Šapić (2012), a uz rijeku Savu do Jakuševca Horvat i dr. (1974).

Prva fitocenološka istraživanja šumâ bijele johe u Hrvatskoj započela su u drugoj polovici prošloga stoljeća (Horvat 1962; Trinajstić 1964, 1973). Horvat (1962) opisuje sastojine bijele johe u Gorskom kotaru, a prva fitocenološka istraživanja šumâ bijele johe u panonskom dijelu njezina areala provodi Trinajstić (1964). Trinajstić (1964) analizira 13 fitocenoloških snimaka i navedene sastojine svrstava u asocijaciju Equiseto hyemali-Alnetum incanae rasprostranjenu u širem alpskom području. Nešto kasnije, i to na temelju istih podataka, raspravlja o njezinu sistematskom položaju te o njezinoj pripadnosti unutar viših sintaksonomskih kategorija (Trinajstić 1973). Budući da je otada prošlo pedesetak godina, mnoge su sastojine iskrčene, antropogeni zahvati promijenili su vodni režim, a staništa i florni sastav biljnih zajednica doživjeli su mnoge promjene (Vrček 2011; Vukelić 2012; Poljak i dr. 2014, 2018).

Cilj je ovoga rada: (1) prikazati rezultate novih istraživanja asocijacije Equiseto hyemali-Alnetum incanae, (2) usporediti ih sa sastojinama iz Gorskoga kotara i (3) definirati ih u kontekstu novih europskih shvaćanja sintaksonomije poplavnih i močvarnih šuma.

\section{MATERIJAL I METODE MATERIAL AND METHODS}

Istraživanja su provedena prema načelima standardne srednjoeuropske fitocenološke škole (Braun-Blanquet 1964).
Analizirano je ukupno 48 fitocenoloških snimaka, po 24 iz svakoga područja. U analizu je uključeno i 11 novih snimaka s varaždinskoga područja. Osam istraživanih ploha nalazilo se uz rubne dijelove Ormuškoga i Varaždinskoga jezera, a tri uz staro korito rijeke Drave. Svi snimci uneseni su u bazu podataka Turboveg (Hennekens i Schaminee 2001). Za klasifikaciju snimaka korištena je klasterska analiza pomoću programskoga paketa PC-ORD 5.0. (McCune i Mefford 2006). Provedenom klasterskom analizom dobiveno je hijerarhijsko stablo, pri čemu je za udruživanje klastera korištena Wardova metoda (Ward's method), a za definiranje udaljenosti između istraživanih objekata Sorensenova (Bray-Curtis) udaljenost.

Znanstveni nazivi viših biljaka usklađeni su prema bazi podataka Flora Croatica Database (Nikolić 2015), a mahovinâ prema Athertonu i dr. (2010). Mahovine nisu evidentirane u svim istraživanjima pa nisu uzete u obzir u statističkoj analizi. Sintaksonomska nomenklatura dijelom slijedi ICPN (Weber i dr. 2000), a dijelom višedimenzionalnu razdiobu vegetacijskih jedinica prema Matuszkiewiczu i Matuszkiewiczu (1981). Sociološka pripadnost vrsta određena je prema Vukeliću (2012).

\section{REZULTATI RESULTS}

Rezultati istraživanja u tablici 1 prikazuju nove fitocenološke snimke asocijacije Equiseto hyemali-Alnetum incanae. U flornom sastavu (tablica 1) evidentirano je 99 vrsta višega 
Tablica 1. Florni sastav asocijacije Equiseto hyemali-Alnetum incanae.

Table 1. Floral composition of the association Equiseto hyemali-Alnetum incanae.

$\begin{array}{lccccccccccc}\text { Broj snimke - Number of relevé } & 1 & 2 & 3 & 4 & 5 & 6 & 7 & 8 & 9 & 10 & 11 \\ \text { Br. snimke u dendrogramu na slici 2 - Nr. in Fig. 2 } & 38 & 39 & 40 & 41 & 42 & 43 & 44 & 45 & 46 & 47 & 48 \\ \text { Površina snimke - Relevé area (m²) } & & & & & 400 & & & & & \\ \text { Nadmorska visina - Altitude (m) } & 165 & 163 & 178 & 180 & 182 & 162 & 189 & 189 & 163 & 185 & 187 \\ \text { Pokrovnost - cover (\%) - drveće - tree layer (a) } & 60 & 80 & 80 & 80 & 60 & 95 & 80 & 80 & 95 & 100 & 95 \\ \text { grmlje - schrub layer (b) } & 75 & 50 & 60 & 70 & 80 & 50 & 80 & 80 & 80 & 50 & 80 \\ \text { prizemno rašćc - herb layer (c) } & 90 & 60 & 100 & 100 & 90 & 85 & 100 & 100 & 60 & 50 & 70\end{array}$

\section{Alnion incanae}

Alnus incana

Ulmus laevis

$\begin{array}{llllllllllll}\text { a } & 3 & 4 & 3 & + & 3 & 3 & 3 & 4 & 3 & 3 & 3\end{array}$

Ulmus minor

Rubus caesius

Viburnum opulus

Alnus incana

Ulmus minor

Ulmus laevis

Quercus robur

Quercus robur

Equisetum hyemale

Festuca gigantea

Rubus caesius

Stellaria nemorum agg.

Carex remota

Impatiens noli-tangere

Fraxinus angustifolia

Chrysosplenium alternifolium

Alnus incana

Ulmus minor

\section{Salicetalia purpureae}

Populus alba

Salix alba

\section{Alnetea glutinosae}

Prunus padus

Alnus glutinosa

Prunus padus

Humulus lupulus

Carex vesicaria

Humulus lupulus

Cardamine pratensis

Prunus padus

\section{Carpinion, Erythronio-Carpinion}

Acer campestre

Lonicera caprifolium

Acer campestre

Galanthus nivalis

Primula vulgaris

\section{Fagetalia}

Sambucus nigra

Pulmonaria officinalis

Paris quadrifolia

Arum maculatum

Anemone ranunculoides

Brachypodium sylvaticum

Symphytum tuberosum agg.

$$
\begin{array}{llllllllllll}
\text { a } & + & + & 3 & 2 & 2 & . & + & . & 1 & . & 1 \\
& + & \cdot & + & 1 & \cdot & 1 & \cdot & . & 3 & 3 & 3 \\
\text { b } & 2 & 2 & 1 & 1 & + & 1 & + & + & 2 & 2 & 3
\end{array}
$$




\begin{tabular}{|c|c|c|c|c|c|c|c|c|c|c|c|}
\hline Broj snimke - Number of relevé & 1 & 2 & 3 & 4 & 5 & 6 & 7 & 8 & 9 & 10 & 11 \\
\hline Br. snimke u dendrogramu na slici 2 - Nr. in Fig. 2 & 38 & 39 & 40 & 41 & 42 & 43 & 44 & 45 & 46 & 47 & 48 \\
\hline Površina snimke - Relevé area $\left(\mathrm{m}^{2}\right)$ & & & & & 400 & & & & & & \\
\hline Nadmorska visina - Altitude (m) & 165 & 163 & 178 & 180 & 182 & 162 & 189 & 189 & 163 & 185 & 187 \\
\hline Pokrovnost - cover (\%) - drveće - tree layer (a) & 60 & 80 & 80 & 80 & 60 & 95 & 80 & 80 & 95 & 100 & 95 \\
\hline grmlje - schrub layer (b) & 75 & 50 & 60 & 70 & 80 & 50 & 80 & 80 & 80 & 50 & 80 \\
\hline prizemno rašće - herb layer (c) & 90 & 60 & 100 & 100 & 90 & 85 & 100 & 100 & 60 & 50 & 70 \\
\hline
\end{tabular}

Circaea lutetiana

Ranunculus ficaria

Asarum europaeum

Heracleum sphondylium

Lamium galeobdolon

Adoxa moschatellina

Allium ursinum

Dryopteris filix-mas

Viola reichenbachiana

Salvia glutinosa

Geranium robertianum

Scrophularia nodosa

Lamium orvala

Leucojum vernum

Carex sylvatica

Gagea lutea

\section{Rhamno-Prunetea}

Cornus sanguinea

Cornus sanguinea

Euonymus europaeus

Ligustrum vulgare

Crataegus monogyna

Clematis vitalba

Clematis vitalba

Cornus sanguinea

Ligustrum vulgare

Euonymus europaeus

\section{Querco-Fagetea}

Corylus avellana

Lonicera xylosteum

Hedera helix

Tamus communis

Lonicera xylosteum

Moehringia trinervia

\section{Galio-Urticetea}

Lamium maculatum

Aegopodium podagraria

Galium aparine

Urtica dioica

Glechoma hederacea

Solidago gigantea

Geum urbanum

Solanum dulcamara

Alliaria petiolata

Veronica hederifolia 


\begin{tabular}{|c|c|c|c|c|c|c|c|c|c|c|c|}
\hline Broj snimke - Number of relevé & 1 & 2 & 3 & 4 & 5 & 6 & 7 & 8 & 9 & 10 & 11 \\
\hline Br. snimke u dendrogramu na slici $2-N r$ in Fig. 2 & 38 & 39 & 40 & 41 & 42 & 43 & 44 & 45 & 46 & 47 & 48 \\
\hline Površina snimke - Relevé area $\left(\mathrm{m}^{2}\right)$ & & & & & 400 & & & & & & \\
\hline Nadmorska visina - Altitude (m) & 165 & 163 & 178 & 180 & 182 & 162 & 189 & 189 & 163 & 185 & 187 \\
\hline Pokrovnost - cover (\%) - drveće - tree layer (a) & 60 & 80 & 80 & 80 & 60 & 95 & 80 & 80 & 95 & 100 & 95 \\
\hline grmlje - schrub layer (b) & 75 & 50 & 60 & 70 & 80 & 50 & 80 & 80 & 80 & 50 & 80 \\
\hline prizemno rašće - herb layer (c) & 90 & 60 & 100 & 100 & 90 & 85 & 100 & 100 & 60 & 50 & 70 \\
\hline
\end{tabular}

Viola odorata

Impatiens glandulifera

Stellaria media

\section{Molinio-Arrhenatheretea}

Lysimachia nummularia

Ranunculus repens

Deschampsia cespitosa

Ajuga reptans

Agrostis stolonifera

Succisa pratensis

Filipendula ulmaria

Valeriana dioica

Poa trivialis

Myosotis scorpioides

\section{Phragmiti-Caricetea elatae}

Carex elata

Iris pseudacorus

Phragmites australis

Lysimachia vulgaris

Caltha palustris

\section{Ostale-0ther species}

Robinia pseudacacia

Tilia sp.

Acer negundo

Juglans nigra

Robinia pseudacacia

Stachys sylvatica

Equisetum arvense

Galeopsis tetrahit

Erigeron annuus

Euphorbia sp.

Eupatorium cannabinum

Chelidonium majus

Koordinate - Coordinate (WGS84)

1. N- $46^{\circ} 19^{\prime} 7.98 \mathrm{E}-16^{\circ} 26^{\prime} 12.72$

2. N- $46^{\circ} 19^{\prime} 7.98 \mathrm{E}-16^{\circ} 26^{\prime} 7.86$

3. N- $46^{\circ} 22^{\prime} 20.58$ E- $16^{\circ} 13^{\prime} 9.12$

4. N-46 $22^{\circ} 24.06 \mathrm{E}-16^{\circ} 13^{\prime} 9.06$

5. N-46 $22^{\prime} 23.10$ E- $16^{\circ} 13^{\prime} 12.12$

6. N- $46^{\circ} 19^{\prime} 8.76$ E- $16^{\circ} 25^{\prime} 58.50$

7. N- $46^{\circ} 23^{\prime} 1.44 \mathrm{E}-16^{\circ} 10^{\prime} 7.44$

8. N-46 $23^{\circ} 0.54$ E- $16^{\circ} 10^{\prime} 9.24$

9. N- $46^{\circ} 19^{\prime} 6.12 \mathrm{E}-16^{\circ} 26^{\prime} 1.32$

10. N-46 $22^{\circ} 40.26 \mathrm{E}-16^{\circ} 10^{\prime} 51.30$

11. N- $46^{\circ} 22^{\prime} 21.00 \mathrm{E}-16^{\circ} 10^{\prime} 45.90$ 
Tablica 2. Razlikovne vrste s postotnim udjelom u sastavu asocijacije Equiseto hyemali-Alnetum incanae: 1. Trinajstić 1964; 2. Naša istraživanja.

Table 2. Differentiating species with the percentage of presence in the composition of the association Equiseto hyemali-Alnetum incanae: 1. Trinajstić 1964; 2. Our research.

\begin{tabular}{|c|c|c|c|}
\hline \multirow{2}{*}{\multicolumn{2}{|c|}{$\begin{array}{l}\text { Broj stupca - Number of column } \\
\text { Broj snimaka - Number of relevés }\end{array}$}} & \multirow{2}{*}{$\begin{array}{c}1 \\
13\end{array}$} & \multirow{2}{*}{$\begin{array}{c}2 \\
11\end{array}$} \\
\hline & & & \\
\hline Salix alba & $a, b$ & 69 & 36 \\
\hline Salix purpurea & & 30 & - \\
\hline Equisetum hyemale & c & 46 & 27 \\
\hline Valeriana dioica & & 46 & 9 \\
\hline Angelica sylvestris & & 30 & - \\
\hline Myosoton aquaticum & & 30 & - \\
\hline Ulmus laevis & a & 4 & 64 \\
\hline Alnus glutinosa & & 7 & 55 \\
\hline Populus alba & & - & 36 \\
\hline Acer campestre & $a, b$ & - & 18 \\
\hline Sambucus nigra & $\mathrm{b}$ & 38 & 100 \\
\hline Humulus lupulus & & 30 & 73 \\
\hline Ligustrum vulgare & & 23 & 64 \\
\hline Corylus avellana & & - & 36 \\
\hline Lonicera xylosteum & & - & 27 \\
\hline Pulmonaria officinalis & c & 38 & 91 \\
\hline Lamium maculatum & & - & 91 \\
\hline Paris quadrifolia & & 38 & 91 \\
\hline Arum maculatum & & - & 82 \\
\hline Galium aparine & & 30 & 82 \\
\hline Stachys sylvatica & & 7 & 73 \\
\hline Galanthus nivalis & & 15 & 64 \\
\hline Hedera helix & & - & 55 \\
\hline Circaea lutetiana & & - & 55 \\
\hline Anemone ranunculoides & & - & 55 \\
\hline Ranunculus ficaria & & 7 & 36 \\
\hline Carex vesicaria & & - & 36 \\
\hline Allium ursinum & & - & 27 \\
\hline Asarum europaeum & & - & 27 \\
\hline Dryopteris filix-mas & & - & 27 \\
\hline Heracleum sphondylium & & - & 27 \\
\hline Equisetum arvense & & - & 27 \\
\hline Adoxa moschatellina & & - & 27 \\
\hline Primula vulgaris & & - & 18 \\
\hline Lamium orvala & & - & 18 \\
\hline
\end{tabular}

bilja, od toga 19 u samo jednom snimku s pokrovnošću +. U sloju drveća bijela joha ima edifikatorsku ulogu, a po učestalosti vrlo je rasprostranjena sremza te nešto manje brijest vez i crna joha. U sloju grmlja osim tih vrsta u preko $80 \%$ ploha ističu se Cornus sanguinea, Sambucus nigra i Rubus caesius. $U$ prizemnom je rašću samo 11 vrsta prisutno u više od 60 \% snimaka, što govori o heterogenosti staništa. U sociološkom smislu florni je sastav izrazito raznolik, a najprošrenije su vrste iz sveze Alnion incanae Pawl. in Pawl. et al. 1928 te zatim one iz reda Fagetalia Pawl. in Pawl. et al. 1928 i razreda Rhamno-Prunetea Rivas Goday et Carbonell ex Tx. 1962. Taj je odnos u velikoj mjeri sukladan sastavu kolinske forme asocijacije Equiseto hyemali-Alnetum incanae koju u austrijskom području opisuju Willner i Grabherr (2007) na osnovi 207 snimaka.

Kako bismo utvrdili promjene u flornom sastavu sastojina bijele johe sa zimskom preslicom, naše smo fitocenološke snimke usporedili s onima iz 1964. godine (Trinajstić 1964). U tablici 2 izdvojeno je 35 vrsta koje upućuju na promjene u staništu i sastavu asocijacije. Iz tablice je jasno vidljivo da je smanjen broj higrofita, a znatno povećan udio mezofilnih vrsta i vrstâ s manje mokrih staništa (stupac 2 , tablica 2), i to posebice iz reda Fagetalia i razreda Querco-Fagetea Br.-Bl. et Vlieger 1937.

Asocijacija Equiseto hyemali-Alnetum incanae uspoređena je sa sastojinama iz Gorskoga kotara, odnosno sa zajednicom Lamio orvalae-Alnetum incanae var. geogr. Helleborus dumetorum, pri čemu je utvrđeno da su dinarske sastojine bijele johe znatno bogatije vrstama. Na istom broju snimaka u Gorskom kotaru nalazi se dvostruko veći broj vrsta višega bilja.

Diferencijacija navedenih sintaksona potvrđena je i rezultatima klasterske analize (slika 2). Na slici 2 jasno se vide dvije skupine snimaka, od kojih prva obuhvaća šume iz sjeverozapadne Hrvatske (I), a druga iz Gorskoga kotara (II). Nadalje, svaka je skupina razdvojena u dvije podskupine. Prva podskupina sastojina uz rijeku Dravu (Ia) obuhvaća pet snimaka iz varaždinskoga područja koje je Trinajstić (1964) izdvojio kao inicijalnu fazu asocijacije, dok druga podskupina (Ib) uključuje ostale snimke. U inicijalnoj fazi razvoja asocijacije izostaju vrste iz optimalne i terminalne faze, primjerice Prunus padus u sloju drveća i grmlja, zatim Aegopodium podagraria, Paris quadrifolia, Pulmonaria officinalis, Ajuga reptans, Geum urbanum, Leucojum vernum i Ranunculus repens u sloju prizemnoga rašća. Također je zabilježen veći udio pionirskih vrsta, kao što su Salix purpurea i Solidago gigantea. Sastojine uz rijeku Kupu dijele se na vlažniji podtip Salix alba (IIb, obale Kupe i polje uz zaselak Vode) i suši podtip Alnus glutinosa (IIa, ostali dio areala).

U tablici 3 izdvojeno je 76 razlikovnih vrsta: sedam za asocijaciju Equiseto hyemali-Alnetum incanae i 69 za asocijaciju Lamio orvalae-Alnetum incanae. Kriterij za njihovo izdvajanje bio je da rastu samo u jednoj asocijaciji barem s $20 \%$ snimaka, ili da je razlika između rasprostranjenosti u asocijacijama veća od $35 \%$. Najviše je razlikovnih vrsta među mezofitima iz sveza Aremonio-Fagion (Ht. 1938) Borhidi in Törek et al. 1989, Tilio-Acerion Klika 1955, Erythronio-Carpinion (Ht. 1938) Marinček in Wallnöfer et al. 1993 i reda Fagetalia (ukupno 33 vrste). Treba još istaknuti da je najvažnija razlikovna vrsta podravskih šuma Prunus padus. 


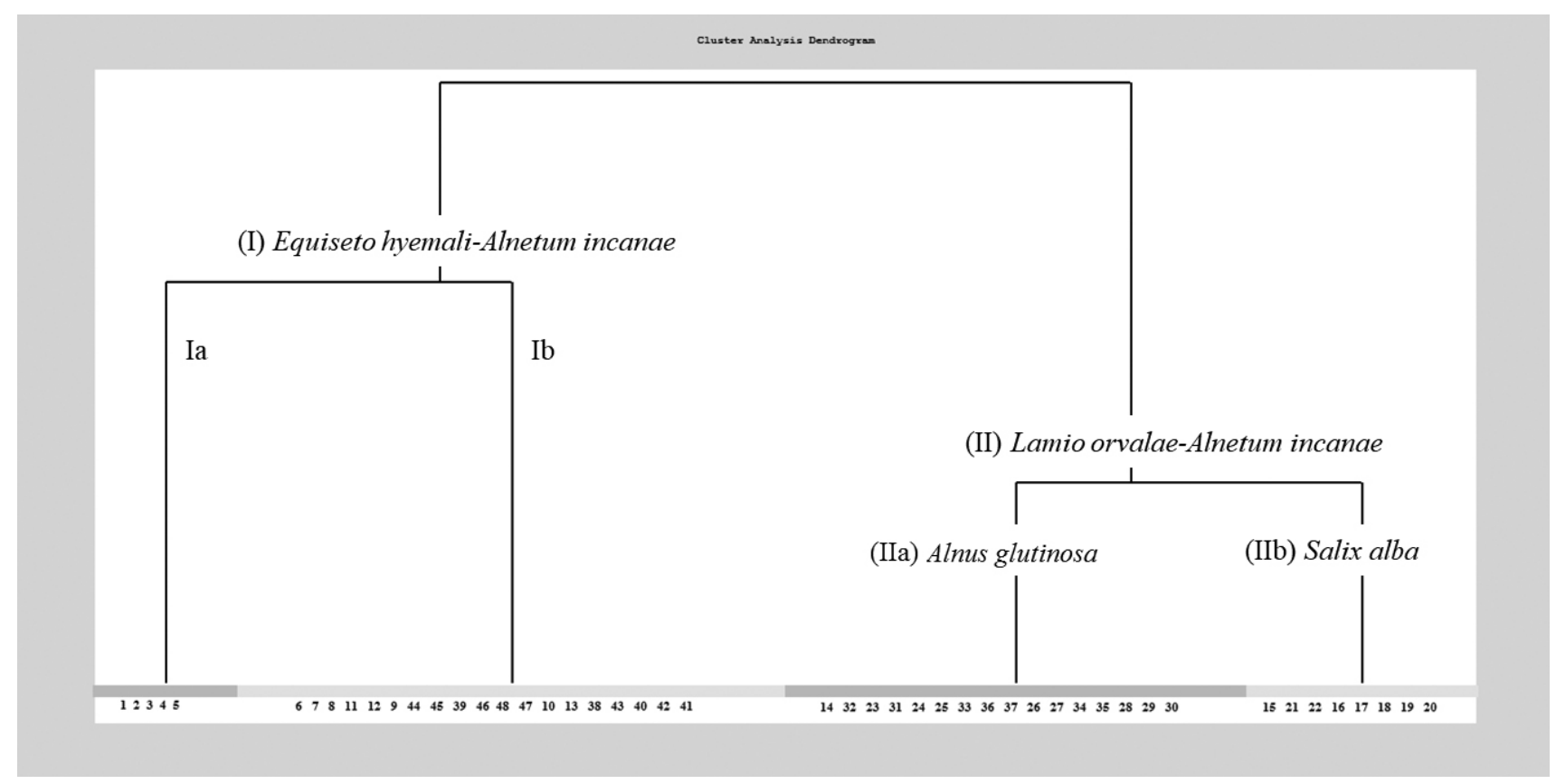

Slika 2. Dendrogram uspoređivanih sastojina bijele johe: (I) Equiseto hyemali-Alnetum incanae, snimci 1-13 (Trinajstić 1964) i 38-48 - naša istraživanja; (II) Lamio orvalae-Alnetum incanae, snimci 15-22 podtip Salix alba (Vukelić i dr. 2017) i 14, 23-37 podtip Alnus glutinosa (Vukelić i dr. 2017).

Figure 2. Dendrogram of the compared grey alder stands: (I) Equiseto hyemali-Alnetum incanae, relevés 1-13 (Trinajstić 1964) and 38-48 - our research; (II) Lamio orvalae-Alnetum incanae, 15-22 subtype Salix alba (Vukelić et al. 2017) and 14, 23-37 subtype Alnus glutinosa (Vukelić et al. 2017)

\section{RASPRAVA}

\section{DISCUSSION}

\section{Dinarsko područje Dinaric area - as. Lamio} orvalae-Alnetum incanae Dakskobler 2010 var. geogr. Helleborus dumetorum Vukelić et al. 2012

Asocijacija Lamio orvalae-Alnetum incanae ustanovljena je u dinarskom i predalpskom biogeografskom području zapadne Slovenije (Dakskobler 2007, 2010). Glavni dio njezina areala u Gorskom kotaru (var. geogr. Helleborus dumetorum) nalazi se uz povremeno plavljeno područje rijeke Kupe i njezinih pritoka, u dužini od tridesetak kilometara. Prosječni pad Kupe u području istraživanja iznosi $2 \mathrm{~m} / \mathrm{km}$. Rijeka mjestimično teče kroz kanjon, a na pojedinim se dijelovima uz nju nižu izdužene terase na kojima su šume u prošlosti iskrčene. Prosječna godišnja temperatura na istraživanom području iznosi oko $11^{\circ} \mathrm{C}$, a prosječna je količina oborina $2200 \mathrm{~mm}$, od čega u vegetacijskom razdoblju padne $43 \%$.

Velik broj razlikovnih vrsta asocijacije Lamio orvalae-Alnetum incanae razvio se zbog više čimbenika. Asocijaciju obilježavaju dvije skupine vrsta: jednu skupinu čine vrste poplavnih i mokrih staništa, česte u sličnim vegetacijskim tipovima u Europi, a drugu mezofilne vrste okolnih zonalnih kitnjakovo-grabovih $\mathrm{i}$ bukovih šuma dinarskoga gorja (sveze Erythronio-Carpinion i Aremonio-Fagion). Među njima se posebno ističu vrste ilirskoga flornoga geoelementa: Lamium orvala, Scopolia carniolica, Knautia drymeia subsp. drymeia, Helleborus dumetorum, H. niger, Primula vulgaris i druge. Biljne vrste zonalnih šuma često prodiru do obale rijeke Kupe, a prelaze i na otoke. Prisutnost vrsta ilirske rasprostranjenosti, pa i nekih termofilnijih elemenata, uglavnom je posljedica biogeografskoga položaja, orografskih čimbenika i refugijalnoga karaktera zapadnih Dinarida - jednoga od florno najbogatijih šumskih područja Europe. Uza sve to važan je i antropogeni čimbenik čiji se utjecaj ogleda u prisutnosti antropofita. Nadalje, veći broj vrsta sveze Tilio-Acerion rezultat je dubljega kanjonskoga toka rijeke Kupe, perhumidne klime i visoke zračne vlage. Mezofilne vrste iz zonalnih hrastovo-grabovih i bukovih šuma rastu na užim padinama i pojasima uz tok rijeka na kojima nema duljega zadržavanja vode. Te vrste prodiru s okolnih obronaka i miješaju se s higrofitima, a dio godine bez velike vlage u tlu omogućuje njihov nesmetani razvoj.

Zanimljivo je da se te šume uvelike razlikuju od šuma bijele johe istočnih i središnjih Dinarida (jugozapadna Srbija, sjeverna Crna Gora, središnja Bosna). Njihov je florni sastav, a samim time i fitocenološka pripadnost, sličan srednjoeuropskim šumama bijele johe, pa i sastojinama iz sjeverozapadne Hrvatske (Vukelić i dr. 2017).

\section{Panonsko područje Panonian area - as. Equiseto} hyemali-Alnetum incanae Moor 1958 (= Alnetum incanae Lüdi 1921 sensu Douda et al. 2016)

Šuma sive johe sa zimskom preslicom razvija se uz brze i aktivne vodotoke u širem alpskom prostoru, najčešće od 
Tablica 3. Razlikovne vrste s postotnim udjelom između asocijacijâ Equiseto hyemali-Alnetum incanae (stupac 1) i Lamio orvalae-Alnetum incanae (stupac 2).

Table 3. Differentiating species with the percentage of presence between the associations Equiseto hyemali-Alnetum incanae (column 1) and Lamio orvalae-Alnetum incanae (column 2).

\begin{tabular}{|c|c|c|c|c|}
\hline & Asocijacija - Association & & 1 & 2 \\
\hline & Broj snimaka - Number of relevés & & 24 & 24 \\
\hline & Alnion incanae, Alnion glutinosae & & & \\
\hline $\mathrm{Ag}$ & Prunus padus & $a, b, c$ & 88 & - \\
\hline & Ulmus minor & & 38 & - \\
\hline & Quercus robur & & 33 & - \\
\hline & Ulmus laevis & & 29 & - \\
\hline 0 & Solidago gigantea & c & 58 & 13 \\
\hline & Equisetum hyemale & & 38 & 4 \\
\hline $\mathrm{F}$ & Anemone ranunculoides & & 25 & - \\
\hline $\mathrm{Ag}$ & Frangula alnus & b & - & 21 \\
\hline & Festuca gigantea & c & 8 & 67 \\
\hline & Impatiens noli-tangere & & 4 & 42 \\
\hline & Carex brizoides & & - & 42 \\
\hline & Chaerophyllum hirsutum & & - & 38 \\
\hline & Carex remota & & 4 & 38 \\
\hline & Cardamine impatiens & & - & 33 \\
\hline & Carex pendula & & - & 33 \\
\hline & Cerastium sylvaticum & & - & 25 \\
\hline $\mathrm{AE}$ & Aremonio-Fagion, Erythronio-Carpinion & & & \\
\hline & Lamium orvala & c & 8 & 88 \\
\hline & Knautia drymeia & & - & 63 \\
\hline & Stellaria nemorum agg. & & 8 & 63 \\
\hline & Helleborus dumetorum & & - & 58 \\
\hline & Primula vulgaris & & 8 & 42 \\
\hline & Helleborus niger & & - & 33 \\
\hline & Scopolia carniolica & & - & 29 \\
\hline & Cardamine trifolia & & - & 25 \\
\hline & Vicia oroboides & & - & 21 \\
\hline & Omphalodes verna & & - & 21 \\
\hline TA & Tilio-Acerion & & & \\
\hline & Acer pseudoplatanus & $a, b, c$ & - & 79 \\
\hline & Ulmus glabra & & - & 50 \\
\hline & Lunaria rediviva & c & - & 33 \\
\hline & Arum maculatum & & - & 33 \\
\hline & Aruncus dioicus & & - & 29 \\
\hline & Aconitum lycoct. vulparia & & - & 21 \\
\hline $\mathrm{F}$ & Fagetalia, Carpinion & & & \\
\hline & Fraxinus excelsior & $a, b, c$ & - & 79 \\
\hline & Carpinus betulus & & - & 54 \\
\hline & Fagus sylvatica & & - & 29 \\
\hline & Lamium galeobdolon & c & 17 & 79 \\
\hline & Circaea lutetiana & & 25 & 67 \\
\hline & Asarum europaeum & & 13 & 63 \\
\hline & Carex sylvatica & & 8 & 58 \\
\hline & Salvia glutinosa & & 8 & 58 \\
\hline & Allium ursinum & & 13 & 50 \\
\hline
\end{tabular}

\begin{tabular}{|c|c|c|c|c|}
\hline & Mercurialis perennis & & - & 50 \\
\hline & Petasites albus & & - & 50 \\
\hline & Ranunculus lanuginosus & & - & 38 \\
\hline & Polygonatum multiflorum & & - & 33 \\
\hline & Cardamine bulbifera & & - & 29 \\
\hline & Campanula trachelium & & - & 25 \\
\hline & Mycelis muralis & & - & 21 \\
\hline & Phyteuma spicatum & & - & 21 \\
\hline \multirow[t]{5}{*}{$\mathrm{QF}$} & Querco-Fagetea & & & \\
\hline & Corylus avellana & $a b$ & 17 & 79 \\
\hline & Anemone nemorosa & c & 4 & 46 \\
\hline & Carex digitata & & - & 21 \\
\hline & Galium sylvaticum & & - & 21 \\
\hline \multirow[t]{3}{*}{ VP } & Vaccinio-Piceetea & & & \\
\hline & Aposeris foetida & c & - & 33 \\
\hline & Oxalis acetosella & & - & 21 \\
\hline \multirow[t]{3}{*}{$\mathrm{RP}$} & Rhamno-Prunetea & & & \\
\hline & Rhamnus cathartica & $b$ & - & 25 \\
\hline & Rubus plicatus & & - & 21 \\
\hline \multirow[t]{5}{*}{$A D$} & Adenostyletalia & & & \\
\hline & Senecio ovatus & c & - & 63 \\
\hline & Athyrium filix-femina & & - & 46 \\
\hline & Doronicum austriacum & & - & 25 \\
\hline & Veratrum album & & - & 21 \\
\hline \multirow[t]{16}{*}{0} & Ostale vrste - Other species & & & \\
\hline & Equisetum arvense & c & 13 & 75 \\
\hline & Lysimachia vulgaris & & 4 & 58 \\
\hline & Eupatorium cannabinum & & 4 & 54 \\
\hline & Deschampsia cespitosa & & 8 & 54 \\
\hline & Petasites hybridus & & - & 50 \\
\hline & Galeopsis speciosa & & - & 50 \\
\hline & Stachys sylvatica & & 4 & 50 \\
\hline & Poa trivialis & & 4 & 46 \\
\hline & Cirsium oleraceum & & - & 42 \\
\hline & Geranium phaeum & & - & 25 \\
\hline & Mentha longifolia & & - & 25 \\
\hline & Mentha aquatica & & - & 25 \\
\hline & Crepis paludosa & & - & 25 \\
\hline & Scirpus sylvaticus & & - & 25 \\
\hline & Juncus effusus & & - & 21 \\
\hline
\end{tabular}

300 do $1400 \mathrm{~m}$. Tako prati i tok rijeke Drave i ulazi u nizinski pojas sjeverozapadne Hrvatske na 190 m nadmorske visine. Taj je prostor svojevrsna dodirna zona alpske i panonske vegetacije, što se odrazilo i na sastav šumâ bijele johe. Na tim područjima bijela joha raste na aluvijalnim naplavinama koje čine valutice različite veličine, a nastale su djelovanjem rijeke Drave. Tla su hidromorfna i manje ili više nerazvijena, neutralne ili slabo kisele reakcije. Prosječna je godišnja temperatura oko $10^{\circ} \mathrm{C}$, a količina oborina oko $900 \mathrm{~mm}$. Bijela je joha rasprostranjena nizvodno Dra- 


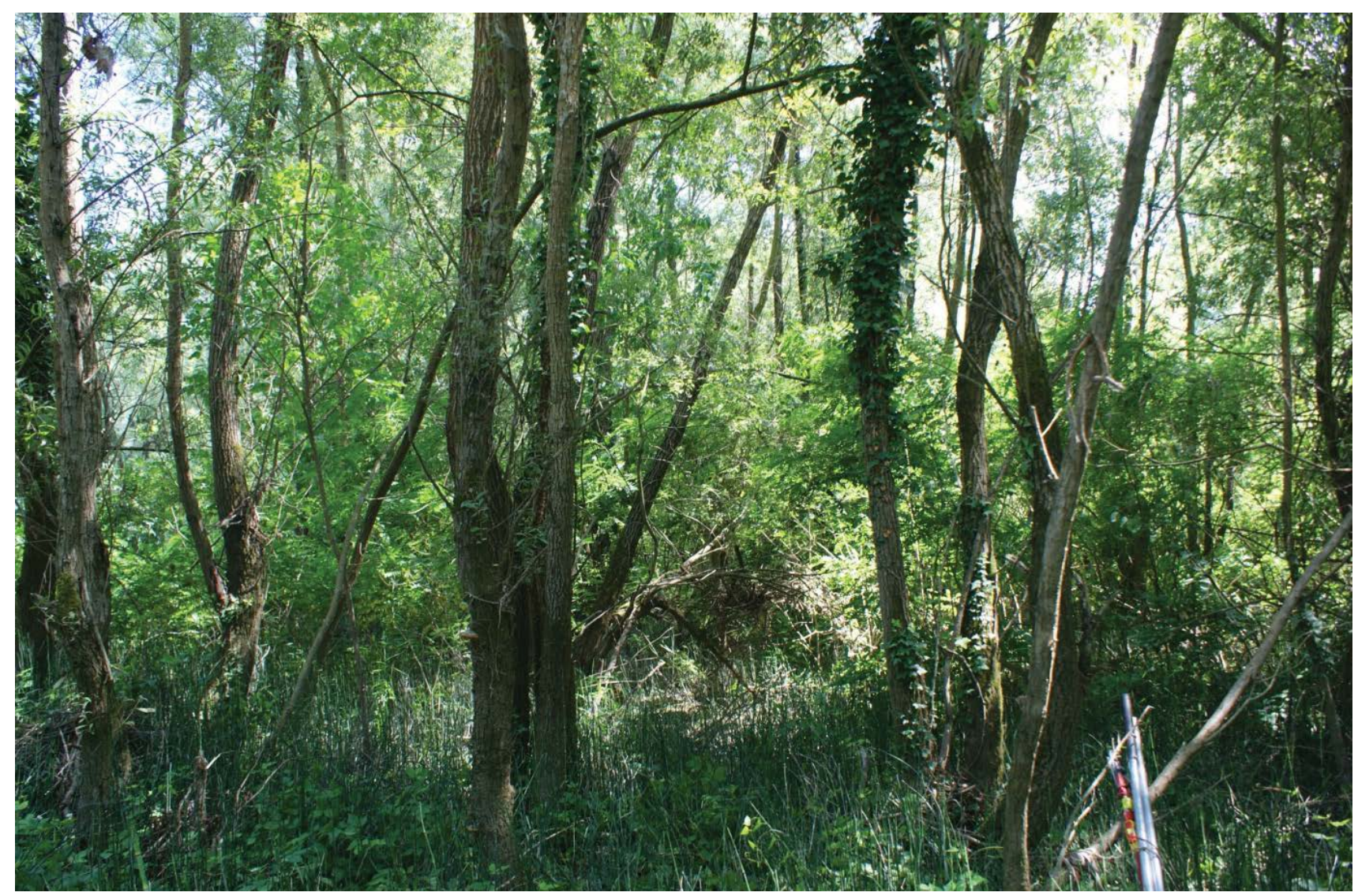

Slika 3. Šuma bijele johe sa zimskom preslicom kod Ormoškoga jezera. U prizemnom sloju dominira Equisetum hyemale. Figure 3. Grey alder-scouring rush forest by Ormoško Lake. The ground layer is dominated by Equisetum hyemale.

vom preko Pažuta, Slatinskih podravskih šuma do Donjega Miholjca, ali ne više kao edifikator u asocijaciji sa zimskom preslicom (Vukelić i dr. 1999; Vrček 2011; Poljak i dr. 2018).

Equiseto hyemali-Alnetum incanae primarno je pionirska zajednica u trajnom stadiju, no nastaje i sukcesijom na zajednicama rakite i ostalih uskolisnih vrba. U flornom sastavu prevladavaju vrste povremeno poplavnih i mokrih staništa, mezofiti su rijetki i učestalo se javljaju u višim položajima ili pak u terminalnoj fazi razvoja ove asocijacije (Trinajstić 1964). U dijagnostičkom smislu posebno se ističu Equisetum hyemale, Prunus padus, Rubus caesius, Sambucus nigra, Humulus lupulus, a s uzvišenjem terena i sušim uvjetima povećava se udio vrsta Cornus sanguinea, Euonymus europaeus i Ligustrum vulgare.

Visinski je raspon areala šume bijele johe sa zimskom preslicom veoma širok pa fitocenolozi u njem razlikuju nekoliko visinskih formi (Müller i Görs 1957; Oberdorfer 1992; Willner i Grabherr 2007). Na rubnim dijelovima Alpa najčešće razlikuju kolinsku (200-600 m n. v.) i montansku (600-1200 m n. v.) formu. Sastojine iz sjeverozapadne Hrvatske florno su vrlo slične kolinskoj formi u šumskoj vegetaciji Austrije (Willner i Grabherr 2007). Budući da sastojine bijele johe u Podravini rastu na nižim nadmorskim visinama, u njima izostaju ili su znatno manje rasprostra- njene vrste: Fraxinus excelsior, Lonicera xylosteum, Cardus perssonata, Picea abies, Anemone ranunculoides, Salvia glutinosa i druge. S druge strane, u njima određeno diferencijalno značenje imaju: Ulmus laevis, U. minor, Quercus robur, Fraxinus angustifolia, Populus alba, Valeriana dioica i druge. Međutim, visok stupanj sličnosti flornoga sastava sa sastojinama bijele johe širega alpskoga područja pokazuje da pripadaju asocijaciji Equiseto hyemali-Alnetum incanae. Velika florna sličnost šuma bijele johe u širem europskom prostoru navela je fitocenologe da u pojedinim vegetacijskim pregledima asocijaciju Equiseto hyemali-Alnetum incanae shvate kao sinonim ranije opisane asocijacije Alnetum incanae Lüdi 1921 (Oberdorfer 1992; Mucina i dr. 1993; Chytrý 2013; Douda i dr. 2016).

Sastojine bijele johe sa zimskom preslicom u Podravini se nalaze u poljoprivredno razvijenom i najgušće naseljenom dijelu Hrvatske, s izgrađenim nasipima, iskopanim dubokim kanalima i akumulacijama (Vukelić 2012; Poljak i dr. 2014). Melioracijama se jako utjecalo na hidrološki režim cijeloga područja (Bušić 1997), što je rezultiralo promjenama u staništu, a u konačnici i nestankom površina koje su nekoć bile pod šumama bijele johe. To potvrđuju i promjene u flornom sastavu. Nekoć široko rasprostranjene vrste poput Equisetum hyemale, Angelica sylvestris i Valeriana dioica se povlače, 


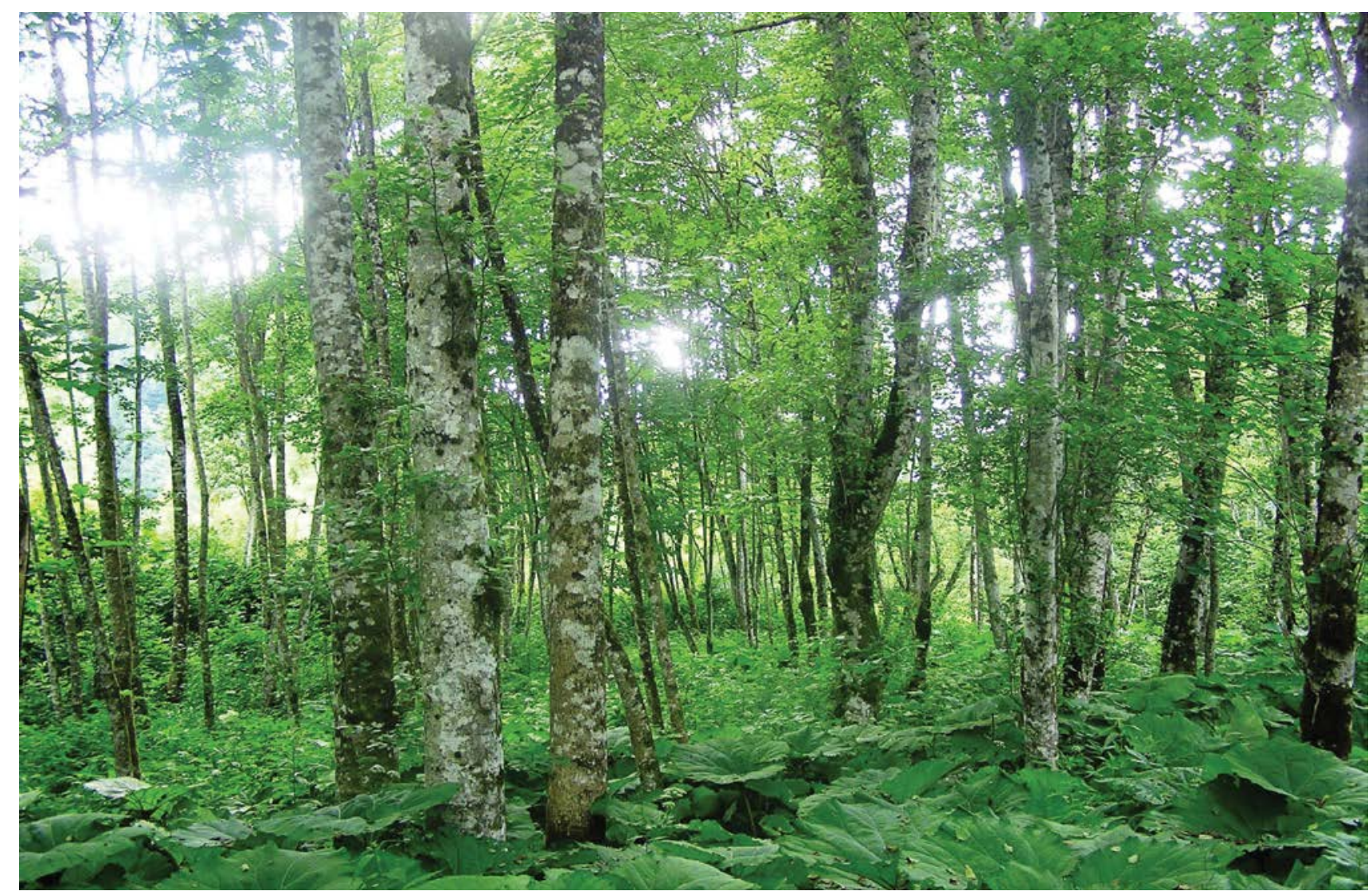

Slika 4. Šuma bijele johe s mrtvom koprivom kod Mele Lešnice u Gorskome kotaru. U prizemnom sloju dominira Petasites hybridus.

Figure 4. Grey alder-balm leaved archangel forest by Mala Lešnica in Gorski kotar. The ground layer is dominated by Petasites hybridus.

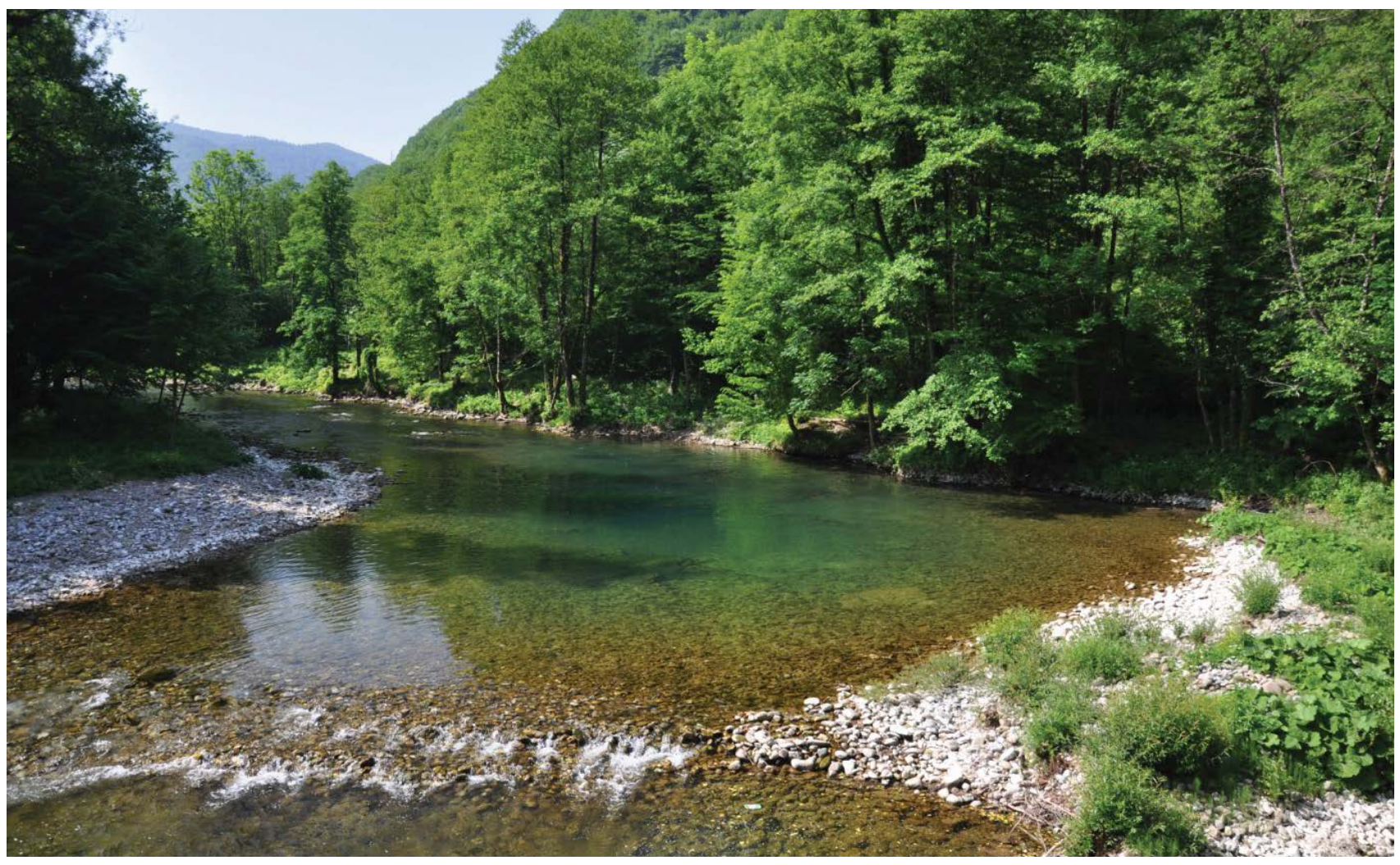

Slika 5. Šumska vegetacija uz Kupu kod Kupara.

Figure 5. Forest vegetation along the Kupa river by Kupari. 
a povećan je udio mezofilnih vrsta i drugih s manje mokrih staništa. Među njima posebice se ističu Hedera helix, Arum maculatum, Circaea lutetiana, Ligustrum vulgare, Pulmonaria officinalis, Corylus avellana, Anemone ranunculoides, $\mathrm{Pa}$ ris quadrifolia, Lamium maculatum i druge. Međutim, ne smijemo zanemariti činjenice da naša istraživanja nisu obuhvatila inicijalnu fazu ove asocijacije te da nisu provedena na istim lokalitetima (Trinajstić 1964), što, među ostalim, potvrđuju starija stabla crne johe i bijele topole koja smo zabilježili u nekim našim plohama. Zbog navedenih procesa uz rijeku Dravu ugrožena je vrsta Equisetum hyemale (Franjić i dr. 1999), a na sličnim staništima u tom području već su nestale Myricaria germanica i Hyppophae rhamnoides.

\section{ZAKLJUČCI CONCLUSIONS}

Na temelju provedenih istraživanja potvrdili smo postojanje dviju asocijacija bijele johe u Hrvatskoj, koje se ekološki i fitocenološki jasno razlikuju. Sastojine iz sjeverozapadne Hrvatske mogu se nedvojbeno uvrstiti u asocijaciju Equiseto hyemali-Alnetum incanae, odnosno u širem europskom kontekstu u asocijaciju Alnetum incanae. Asocijacija Lamio orvalae-Alnetum incanae iz Gorskoga kotara, odnosno sjeverozapadnih Dinarida, pokazuje veliku samostalnost u odnosu na ostale šume bijele johe u Europi pri čemu i rezultati ovih istraživanja potvrđuju njezin neosporni identitet. Njihove florne razlike uvjetovane su u prvom redu razlikama u biogeografskim područjima i zonalnim šumama u čijem pojasu rastu. Postojanje jasnih razlika između kontinentalnih i alpsko-dinarskih sastojina bijele johe potvrđuju i Poljak i dr. (2018) morfometrijskim metodama.

U sintaksonomskom smislu analizirane asocijacije Equiseto hyemali-Alnetum incanae i Lamio orvalae-Alnetum incanae svrstavaju se u podsvezu Alnenion glutinoso-incanae Oberd. 1953, svezu Alnion incanae Pawl. in Pawl. et al. 1928, red Fagetalia sylvaticae Pawl. in Pawl. et al. 1928 i razred Querco-Fagetea Br.-Bl. et Vlieger 1937.

Zbog velikih antropogenih zahvata i promjene namjene zemljišta u širem prostoru, šuma bijele johe sa zimskom preslicom doživjela je u Podravini znatne regresivne promjene u rasprostranjenosti i flornom sastavu, pa se kao i vrsta Equisetum hyemale treba smatrati ugroženim stanišnim tipom. Rezultati naših istraživanja izravno pridonose poznavanju njezina flornoga sastava, sindinamike i varijabilnosti, a mogu biti i veoma važni za očuvanje preostalih lokaliteta.

\section{ZAHVALE}

\section{ACKNOWLEDGEMENTS}

Za financijsku potporu istraživanjima zahvaljujemo Hrvatskoj zakladi za znanost (projekt IP-2014-09-1834) i Ministarstvu poljoprivrede Republike Hrvatske (projekt Vegetacijska i genetička varijabilnost roda Alnus Mill. u Hrvatskoj).

\section{LITERATURA}

\section{REFERENCES}

- Amigo, J., J. Izco, I. Romero, 2004: Swamp alder woodlands in Galicia (NW Spain): phytosociological interpretation. Ecological and floristic contrast to western European swamp woodlands and delimitation versus riparian alder woodlands in southern Europe and northern Africa, Phytocoenologia 34: 613-638.

- Atherton, I., S. Bosanquet, M. Lawley (ur.), 2010: Mosses and liverworts of Britain and Ireland a field guide, British Bryological Society, 848 str., London.

- Braun-Blanquet, J., 1964: Pflanzensoziologie. Grundzüge der Vegetationskunde, Springer, 631 str., Wien - New York.

- Bušić, G., 1997: Proizvodnost fluvisola varaždinske Podravine u odnosu na uspijevanje bijele topole (Populus alba L.), Magistarski rad, Šumarski fakultet Sveučilišta u Zagrebu.

- Chytrý, M. (ur.), 2013: Vegetace České republiky - Lesní a křovinná vegetace, Academia Praha, 551 str., Prag.

- Coldea, G., T. Ursu, 2016: A syntaxonomic revision of floodplain forest communities in Romania, Tuexenia 36: 9-22.

- Dakskobler, I., 2007: Fitocenološka in floristična analiza obrečnih gozdov v Posočju (zahodna Slovenija), Razprave 4. razreda SAZU (Ljubljana) 48 (2): 25-138.

- Dakskobler, I., 2010: Razvoj vegetacije na prodišćih reke Idrijce v zahodni Sloveniji, Folia biologica et geologica 51 (2): 5-90.

- Dierschke, H., 1984: Zur syntaksonomischen Stellung und Gliederung der Ufer- und Auenwälder Südeuropas, Coll Phytosoc 9: 115-129.

- Döring-Mederake, U., 1990: Alnion forests in Lower Saxony (FRG), their ecological requirements, classification and position within Carici elongatae-Alnetum of Northern Central Europe, Vegetatio 89: 107-119.

- Douda, J., 2008: Formalized classification of the vegetation of alder carr and floodplain forests in the Czech Republic, Preslia 80: 199-224.

- Douda, J., K. Boublik, M. Slezak, M. Biurrun, I. Nociar, J. Havrdova i dr., 2016: Vegetation classification and biogeography of European floodplain forests and alder carrs, Appl Veg Sci 19: 147-163.

- Franjić, J., I. Trinajstić, Ž. Škvorc, M. Presečan, I. Samardžić, 1999: A contribution to the knowledge of the distribution of Equisetum hyemale L. (Equisetaceae) in Croatia, Nat Croat 8 (2): 95-100.

- Hennekens, S. M., J. H. J. Schaminée, 2001: TURBOVEG, a comprehensive data base management system for vegetation data, J Veg Sci 12: 589-591.

- Horvat, I., 1962: Vegetacija planina zapadne Hrvatske, Acta biologica 2 (30): 1-179.

- Horvat, I., V. Glavač, H. Ellenberg, 1974: Vegetations Südosteuropas, G. Fischer Verlag, 768 str., Stuttgart.

- Matuszkiewicz, W., A. Matuszkiewicz, 1981: Das Prinzip der mehrdimensionalen Gliederung der Vegetationseinheiten, erläutet am Beispiel der Eichen-Hainbuchenwalder in Polen, U: H. Diersche (ur.): Syntaxonomie, Ber. Int. Symp. Int. Vereinig. Vegetationsk. Rinteln 1980, 123-148, Vaduz.

- Müller, T., S. Görs, 1958: Zur Kenntnis einiger Auenwaldgesellschaften im Württembergischen Oberland, Beitr Naturk Forsch Südwestdtschl 17: 88-165. 
- McCune, B., M. J. Meford, 2006: PC-ORD. Multivariante analysis of ekological data. Version 5. MjM Software, Glenden Beach, OR.

- Mucina, L., G. Grabherr, S. Wallnöfer, 1993: Die Pflanzengesellschaften Östereichs, Teil III: Wälder und Gebüsche, Gustav Fischer Verlag, 353 str., Jena - Stuttgart - New York.

- Nikolić, T. (ur.), 2015: Flora Croatica, baza podataka. On-line (http:/hirc.botanic.hr/fcd). Botanički zavod, Prirodoslovnomatematički fakultet, Sveučilište u Zagrebu (pristupljeno 15. prosinca 2017).

- Oberdorfer, E., 1992: Süddeutsche Pflanzengessellschaften IV. Wälder und Gebüsche. 2. Stark bearbeitwete Auflage, Textband, Gustav Fischer, 238. str., Jena - Stuttgart - New York.

- Pielech, R., 2015: Formalised classification and environmental controls of riparian forest communities in the Sudetes (SW Poland), Tuexenia 35: 155-176.

- Poljak, I., M. Idžojtić, I. Šapić, J. Vukelić, M. Zebec, 2014: Varijabilnost populacija bijele (Alnus incana /L./ Moench) i crne (A. glutinosa /L./ Gaertn.) johe na području Mure i Drave prema morfološkim obilježjima listova, Sumar List 138 (1-2): 7-17.

- Poljak, I., M. Idžojtić, I. Šapić, P. Korijan, J. Vukelić, 2018: Diversity and structure of Croatian continental and Alpine-Dinaric populations of grey alder (Alnus incana /L./ Moench subsp. incana): Isolation by distance and environment explains phenotypic divergence, Sumar List 142 (1-2): 19-32.

- Sburlino, G., L. Poldini, C. Andreis, L. Giovagnoli, S. Tasinazzo, 2012: Phytosociological overview of the Italian Alnus incanarich riparian woods, Plant Socyology 49 (1): 39-53.

- Schwabe, E., 1985: Monographie Alnus incana-reicher Waldgesellschaften in Europa. Variabilität und Änlichkeiten einer azonal verbreitete Gesellschaftsgruppe, Phytocoenologia 13 (2): 197-302.

- Slezák, M., R. Hrivnák, A. Petrášová, 2014: Numerical classification of alder carr and riparian alder forests in Slovakia, Phytocoenologia 44 (3-4): 283-308.
- Šapić, I., 2012: Šumska vegetacija Zrinske gore, Disertacija, Šumarski fakultet Sveučilišta u Zagrebu.

- Šegulja, N., Lj. Ilijanić, Lj. Marković, 1998: Prikaz i analiza flore Zrinske gore, Acta Bot Croat 55-56: 65-99.

- Trinajstić, I., 1964: Vegetacija obalnog područja rijeke Drave u široj okolici Varaždina, Magistarski rad, Prirodoslovnomatematički fakultet Sveučilišta u Zagrebu.

- Trinajstić, I., 1973: Über die systematische Stellung der Grauerlenwälder in Nordkroatien. Ber. Geobot. Inst. ETH, Stiftung Rübel, Zürich 51: 111-115.

- Vrček, M., 2011: Siva joha (Alnus incana L.) u šumskim zajednicama varaždinskog područja, Diplomski rad, Šumarski fakultet Sveučilišta u Zagrebu.

- Vukelić, J., 2012: Šumska vegetacija Hrvatske. Sveučilište u Zagrebu, Šumarski fakultet i Državni zavod za zaštitu prirode, 404 str., Zagreb.

- Vukelić, J., D. Baričević, Z. Perković, 1999: Vegetacijske i druge značajke zaštićenog dijela "Slatinskih podravskih šuma”, Sumar List 123 (7-8): 287-299.

- Vukelić, J., D. Baričević, I. Šapić, 2012: Phytocoenological characteristics of forests of grey alder (Alnus incana /L./ Moench) in Gorski kotar, Nat Croatica: Periodicum Musei Historiae Naturalis Croatici 21 (1): 49-64.

- Vukelić, J., I. Šapić, A. Alegro, V. Šegota, I. Stankić, D. Baričević, 2017: Phytocoenological analysis of grey alder (Alnus incana L.) forests in the Dinarides of Croatia and their relationship with affiliated communities, Tuexenia 37: 65-78.

- Weber, H. E., J. Moravec, J.-P. Theurillat, 2000: International code of phytosociological nomenclature, $3^{\text {th }}$ Ed., J Veget Sci 11: 739-768.

- Willner, W., G. Grabherr (ur.), 2007: Die Wälder und Gebüsche Österreichs (1 Textband, 2 Tabellenband), Elsevier, Spektrum Akademischer Verlag, Wien.

\section{Summary}

This paper provides a comprehensive survey of the results of phytocoenological research of Alnus incana (L.) Moench subsp. incana stands in Croatia. Here, the grey alder appears in two biogeographic regions with contrasting climates (Figure 1): the continental region, along the course of the Drava river; and the mountainous Alpine-Dinaric region in Gorski kotar, along the course of the Kupa river and its tributaries. In the continental region of Croatia, the grey alder occurs mainly in riparian and floodplain forests along the main watercourse of the river Drava, where it forms smaller and isolated stands. These stands are included within the association Equiseto hyemali-Alnetum incanae Moor 1958 (Figure 3). Stands from the north-western Dinarides are defined within the association Lamio orvalaeAlnetum incanae Dakskobler 2010 var geogr. Helleborus dumetorum Vukelić et al. 2012 (Figure 4, Figure 5).

Our main objectives were: (1) to present the results of recent studies of the association Equiseto hyemali-Alnetum incanae; (2) to compare them with the results of the studies from early second half of the 20th century (Trinajstić 1964, 1973); and (3) to compare them with the phytocoenological characteristics of grey alder forests from the Dinaric area of Croatia.

The research was conducted on the basis of 11 new phytocoenological relevés and 37 from previous studies, according to the principles of the standard Central European Phytocoenological School (BraunBlanquet 1964). Plant nomenclature was coordinated with the Flora Croatica Database (Nikolić 2015), and the mosses with Atherton et al. (2010). A part of the syntaxa was described in accordance with ICPN (Weber et al. 2000), and another part follows a multidimensional classification of vegetational 
units (Matuszkiewicz and Matuszkiewicz 1981). The sociological species affiliation was determined according to Vukelić (2012). The analysis of the floral composition of the association Equiseto hyemaliAlnetum incanae (=Alnetum incanae Lüdi 1921) from north-western Croatia demonstrates a high degree of floral similarity with colline stands of the same association presented in the forest vegetation of Austria (Willner and Grabherr 2007). As grey alder stands in Podravina grow on lower altitudes, they lack or have considerably less of the following species: Fraxinus excelsior, Lonicera xylosteum, Cardus perssonata, Picea abies, Anemone ranunculoides, Salvia glutinosa and others. On the other hand, some species in them have certain differential significance, namely: Ulmus laevis, U. minor, Quercus robur, Fraxinus angustifolia, Populus alba, Valeriana dioica and others. Table 1 shows 11 new relevés of grey alder-scouring rush stands. Due to major anthropogenic interventions, grey alder-scouring rush forests have seen considerable regressive changes in the distribution and floral composition, hence just like the species Equisetum hyemale, they should be considered an endangered type of habitat. A large part of the original forests and shrubbery has been cleared over the last 50 years due to the construction of two accumulation lakes and other melioration and infrastructural needs. Meliorations have greatly impacted the hydrological regime of the entire area, which resulted in alterations in the habitat, and eventually in the disappearance of areas that used to be covered by grey alder forests. In order to determine the changes in the floral composition of grey alder-scouring rush stands, we compared our phytocoenological relevés with those from 1964 (Trinajstić 1964). Table 2 specifies 35 species that indicate changes in the habitat and composition of the association. The table clearly demonstrates that the number of hygrophytes has been reduced, and the share of mesophilic species and species from less wet habitats considerably increased (column 2, table 2), especially from the order Fagetalia and class Querco-Fagetea Br.-Bl. et Vlieger 1937.

The association Equiseto hyemali-Alnetum incanae has been compared with the stands from Gorski kotar, i.e. with the association Lamio orvalae-Alnetum incanae, where it was found that they differ significantly both from the ecological and from the floral point of view (Figure 2). Floral differences of the said forest communities result primarily from the climate and orographic factors of biogeographic regions, and the share of species from zonal forests in whose belts they grow. Table 3 specifies 76 differentiating species: seven for the association Equiseto hyemali-Alnetum incanae and 69 for the association Lamio orvalae-Alnetum incanae. The criterion employed to single them out was that they grow in only one association with at least $20 \%$ of relevés, or that the difference between the level of representation in associations is in excess of 35\%. The largest number of differentiating species are mesophytes from the alliances Aremonio-Fagion /Ht. 1938/ Borhidi in Törek et al. 1989, Tilio-Acerion Klika 1955, Erythronio-Carpinion (Ht. 1938) Marinček in Wallnöfer et al. 1993 and the order Fagetalia (33 species in total). The large number and frequency of those differentiating species is the reason for clear independence and identity of the association Lamio orvalae-Alnetum incanae compared to other European grey alder forests (Vukelić et al. 2017). The most important differentiating species of the association Equiseto hyemali-Alnetum incanae is Prunus padus. With regard to syntaxonomy, the analyzed associations Equiseto hyemali-Alnetum incanae and Lamio orvalae-Alnetum incanae belong to the suballiance Alnenion glutinoso-incanae Oberd. 1953, alliance Alnion incanae Pawl. in Pawl. et al. 1928, of the order Fagetalia sylvaticae Pawl. in Pawl. et al. 1928 and class Querco-Fagetea Br.-Bl. et Vlieger 1937.

KEY WORDS: Alnus incana, Lamio orvalae-Alnetum incanae, Equiseto hyemali-Alnetum incanae, floral composition, Croatia 